\title{
THE EFFECT OF SPATIAL DIFFERENCES ON THE QUALITY OF URBAN LIFE A COMPARATIVE ANALYTICAL STUDY OF THREE CITIES IN THE HIGH PLATEAUX REGION OF ALGERIA
}

\author{
Ahmed ALLAL* \\ University of M'sila, Urban Technology Management Institute, Urban Technologies and \\ Environment Laboratory, Department of City Management, Algeria, e-mail: ahmed.allal@univ-msila.dz.
}

\author{
Khalfallah BOUDJEMAA \\ University of M'sila, Urban Technologies and Environment Laboratory, \\ Department Of City Management, Algeria, e-mail: boudjemaa.khalfallah@univ-msila.dz.
}

\section{Salim DEHIMI}

University of M'sila, Urban Technologies and Environment Laboratory, Department of Urban Engineering, Algeria, e-mail: salim.dehimi@univ-msila.dz.

\author{
Citation: Allal, A., Boudjemaa, K., \& Dehimi, S. (2022). THE EFFECT OF SPATIAL DIFFERENCES ON THE QUALITY \\ OF URBAN LIFE A COMPARATIVE ANALYTICAL STUDY OF THREE CITIES IN THE HIGH PLATEAUX REGION \\ OF ALGERIA. GeoJournal of Tourism and Geosites, 40(1), 181-190. https://doi.org/10.30892/gtg.40122-818
}

\begin{abstract}
The urban areas in Algeria suffer from several imbalances in different regions, where the inequality of opportunities has led to an imbalance in the population density "from north to south". And to the urban chaos, this matter made it face many challenges, which prompted us to search for this defect. Development plans in Algeria focus on the role of cities with high hills in restoring balance to the national sphere and reducing these disparities. The study aims to extract and evaluate the spatial differences of the three cities and reveal the spatial disparities, in order to establish a balanced regional development, while preparing the various development plans, based on several criteria by integrating the Delphi method with the analytical hierarchy process, and determining its spatial regions in the (GIS) environment. Through a comparative study of three cities, the study showed the progress of the city of Setif, achieving (11\%) of the study area, achieving high qualit $y$, with an area $\left(14.50 \mathrm{~km}^{2}\right)$, Al-M'sila $(03 \%)$ with an area $\left(7.99 \mathrm{~km}^{2}\right)$. Barika $(01 \%)$ with an area of $(3.98 \mathrm{~km} 2)$. The results can be used during the preparation of development plans for this region.
\end{abstract}

Key words: Spatial Differences, Analytic Hierarchy Process (AHP), Geographical Information Systems (GIS), high plateaux region, Quality of life urban (QOL), Algeria

\section{INTRODUCTION}

The principle of balance is a component of the general principles of national development, as every country tries to achieve its spatial harmony and complementarity. National integration is a process aimed to distinguish the borders clearly to remove barriers and differences of any kind among the population (Cote, 2010). The researcher (Cote, 2010) concluded that "the country should go towards a wide redeployment of activities and population on the national soil, through a national movement towards the south", as being the appropriate approach, based mainly on a program called (High Plateaux). The researcher also deduced that it is necessary to review the distribution of the population, as we need this move to achieve a new homogeneity in society and strengthening the social cohesion in cities. It all comes down to a model that sets up rules and works on establishing a balanced and real development to reduce the spatial differences and disparities in the Algerian cities. Maier, 2009 considers that "multi-center development is an effective way to reduce regional imbalance and enhance its cohesion" (Maier, 2009). The researcher here aims to reduce and curb regional imbalances by working on what is known as regional polarization to address these imbalances and differences of any kind. There is no doubt that the urban network as being the backbone / backbone of the regional system - multi-centering, which ensures an effective and coordinated transition for development across the entire region (Humeau et al., 2010).

The urban areas are major centers for economic, social and political growth in any country, and they have proven to be the most attractive places for the creation of wealth, job opportunities, creativity and innovation. This is in light of the challenges posed by development policies and their prospects in each city (Fouad and Sawsan, 2020). Its primary goal should be to please the human being and provide him with a better life.

However, the latter faces major challenges related to the negative aspects of urban development, many urban areas are facing increasing pressures due to population expansion, limited resources, social and economic challenges, and the growing effects of climate change. Therefore, we have to work on addressing these different challenges so that cities can provide quality, healthy and sustainable living environments. World Health Organization, 2020; Sarcheshmeh et al., 2020, as policy makers and planners have focused on the ability of (QOUL) to address these issues largely frequent in cities

\footnotetext{
* Corresponding author
} 
(Montgomery, 2007), as well as working on implementing regional polarization, which aims to reduce regional and spatial imbalances (Grigorescu and Kucsicsa, 2017). In fact, improving the (QOL) in every society is one of the important goals of public policies in recent years, as studies on quality of life have focused mainly on urban nature, and have gained a lot of interest among researchers. Urban planners used the (Multi Criteria Decision Analysis) (MCDA) integration strategy to address spatial issues starting from the 1990s ( $\mathrm{Su}$ et al., 2010). It is clear that the increasing urban population and the mounting trend to live in the city is one of the main incentives for expanding an independent movement in the field of (QOL) research, this movement has led to various interpretations, and thus making it difficult to investigate.

So recent research on quality of life focuses on the quality of measuring this concept in cities (Solaimani et al., 2009).

Thus, social justice means the equitable spatial distribution of facilities and resources in different areas of the city and people's access to them (Moghadam et al., 2016). As a result, decision-makers and planners' most important task is to seek to attain the ideal of "equal opportunity" regarding the accessibility to services for different groups of urban society and to eliminate any inconsistency in providing equal, appropriate education, health and services, as the lack of specific urban development policies created in an ultimately mono-centered and unbalanced urban system (Pascariu, 2010).

Algerian cities are witnessing different problems (spatial and functional), related to many aspects that have repercussions on all aspects of life. Despite its development, growth and increasing numbers of inhabitants, the Algerian cities did not attain the developed cities level in terms of ease of living that varies according to equipment, facilities, basic structures and services; and in which the same living frame for the population is not offered equally, as the big cities are usually the most organized and polarized because of the better requirements that the population needs, while the internal cities have much more less, and some of them lack many essential needs for living, as the National Urban Planning Scheme (SNAT) and the Regional Scheme for Planning and Territory (SRAT) focus on the role of the high plateaux cities in bringing those needs to the population and rebalancing the national territory that suffers from extreme concentration of residents in the North. The study aims to extract and evaluate the spatial differences of the three cities and reveal the spatial disparities, in order to establish a balanced regional development, while preparing the various development plans.

\section{MATERIALS AND METHODS}

\section{Study area}

This research was conducted on the high plateaux region by selecting three cities with the same social, cultural and natural environment: Setif, M'sila, and Barika. These centers are located in Algeria's high plateaux region. The provinces area is $\left(666.01 \mathrm{~km}^{2}\right)$, which represents $(0.027 \%)$ of the country. Setif is the capital of the high plateaus, a state located in northeastern Algeria, $(330 \mathrm{~km})$ from the capital Algiers. It lies within the following geographical coordinates: between longitude: $6.26^{\circ}$ and $5.04^{\circ}$ east of Greenwich, and between latitudes $34.76^{\circ}$ and $26.36^{\circ}$; north of the equator. It is the second largest province after Algiers in terms of population density, with an estimated population of 1,699,738 inhabitants in 2013 census. It is considered as a great economic and inevitable tourism crossing. Estimated area: $\left(130.89 \mathrm{~km}^{2}\right)$, i.e. $(1.7 \%)$ of the eastern plateau area (Figure 1). The city of M'sila is one of the most prominent inland cities in the high hills region of Algeria. It is located within the following geographical coordinates: Between two widths: Circles: $35.48^{\circ}$, ' $35.67^{\circ}$ north of the equator. Between the two longitudes: $4.57^{\circ}, 4.48^{\circ}$ east of Greenwich, which is the line that connects north and south. Since the city is located in the middle of the Tell Atlas and the Saharan Atlas, it is also distinguished by its natural and economic diversity. The area of the municipality is estimated at $\left(232.03 \mathrm{~km}^{2}\right)$, inhabited by 214,661 people, and the population density is estimated at: 925 people, according to the Department of Municipal Statistics 2014.

The study area, which is the urban center of the city, is estimated at: $\left(50.01 \mathrm{~km}^{2}\right)$ Figure 1 . The city of Barika is one of the inner cities of the High Hills region and is located within the following geographical coordinates: between latitudes $35^{\circ}$ and $36^{\circ}$ North, and latitudes $4^{\circ}$ and $5^{\circ}$ East, not far from the main urban centers (the main city of Batna: (88 km), Biskra: (78 km), M'sila: $(99 \mathrm{~km})$, Setif: $(116 \mathrm{~km})$, the municipality of Barika is $\left(303.12 \mathrm{~km}^{2}\right)$, with a population of 114,479 in 2015 census. The main center, itself, represents $(94.13 \%)$ of the total municipality; this justifies the primacy of urban areas over the countryside. This crossroads site provides a hub for dynamic business exchange (Figure 1).

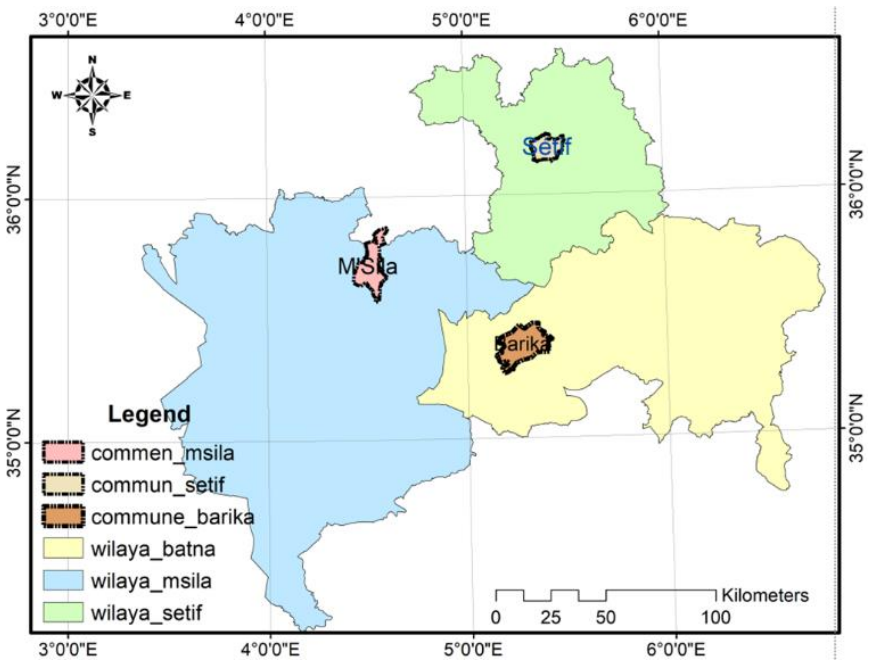

Figure 1. The location of the study area

\section{Data Collection}

\section{Standards for detecting spatial disparities}

These criteria were determined by employing the Delphi method for assessing the (QOL) in urban areas through the application of (MCDA) in decision-making through the (AHP) process. After collecting geographic data, master and sub-factor layers are defined in (QGIS), where criteria are used to clarify concepts for a wide range of users.

1.1. Security and Protection: Development in its multiple dimensions cannot be imagined in the absence of appropriate human capabilities (Sorin and Sebastian, 2018) as a criterion for security and protection.

In this standard, information was collected through a field survey of all security service centers and civil protection centers in the three cities, and then a layer was created for this information in the program (QGIS). 
The security services and civil protection centers were selected on the basis of expert opinions and field surveys to determine the scope of service: less than $2000 \mathrm{~m} ; 2000 \mathrm{~m}$ to 3000m; more than $3000 \mathrm{~m}$ (Figure 2).

1.2. Education: The quality of life depends on education and all the factors that influence it, and it can be said that the greater the investment in education, the greater the possibility of improving the (QOL).

In the same way, we collected all the metadata from the directorates of education for the three cities and all the spatial data from the planning and reconstruction plans with the addition of a field survey to update all the data we have collected. As for the service range, experts specify: less than 500m; 500m to $800 \mathrm{~m}$; more than $800 \mathrm{~m}$ (Figure 2).

1.3. Public Services: In the era of globalization, the dominant trend of development has been regional integration (Aigerim et al., 2021), and the improvement of the (QOL), which leads to the intensive exchange of goods, services and labor resources. Improving the type of service, in turn, enhances the integration of operations as a factor of economic integration of services. In the same way, we depended on the collection and employment of all necessary public services distributed over the city, including municipal branches, postal service offices, telephone service offices, water supply service, urban transport service, and most religious facilities. Work was done to collect data from planning and reconstruction plans for the three cities, for the latest update of field surveys to update the data. Experts defined the range of services as less than $800 \mathrm{~m} ; 800 \mathrm{~m}$ to $1300 \mathrm{~m}$; more than $1300 \mathrm{~m}$ (Figure 2).

1.4. Health: Life-cycle health care can help improve and develop (QOL), in the same way, information was collected on the basis of planning and reconstruction plans for the three cities, with a field survey to work on updating all the data collected. After that, a layer was created for all health service centers and hospitals. Through the same process, service ranges are determined by expert opinions as: less than $800 \mathrm{~m} ; 800 \mathrm{~m}$ to $1500 \mathrm{~m}$; more than $1500 \mathrm{~m}$ (Figure 2).

1.5. Culture and Entertainment: Although recreation and leisure are among the most important urban activities in cities, which have become tourist attractions, they are subject to urban planning in their availability and distribution to ensure quality and quality (Fouad and Sawsan, 2020). We have adopted in this criterion all recreational and recreational centers, including public parks, sports facilities of all forms and types, theatres, culture houses, cinemas, theaters, youth centers and all centers related to social and cultural aspects. The service ranges were based on expert opinions, and various data were collected from the directorate of youth and sports and the directorate of culture for the three cities. Service range is defined as less than $800 \mathrm{~m}, 800 \mathrm{~m}$ to $1500 \mathrm{~m}$; more than $1500 \mathrm{~m}$ (Figure 2).

1.6. Environment: Man can exploit the natural environmental potential in various ways to support the social and economic well-being of the community to improve the (QOL). It is also not possible to separate human life from its environment, because environmental factors have a great impact on human life (Marlina et al., 2021).

In this criterion, different green spaces are identified and classified in addition to forests, agricultural fields, water basins, various residential areas, and the arid areas of the three cities, data were collected from master planning and urbanization plans for each city (Ouzir et al., 2021) (Figure 2).
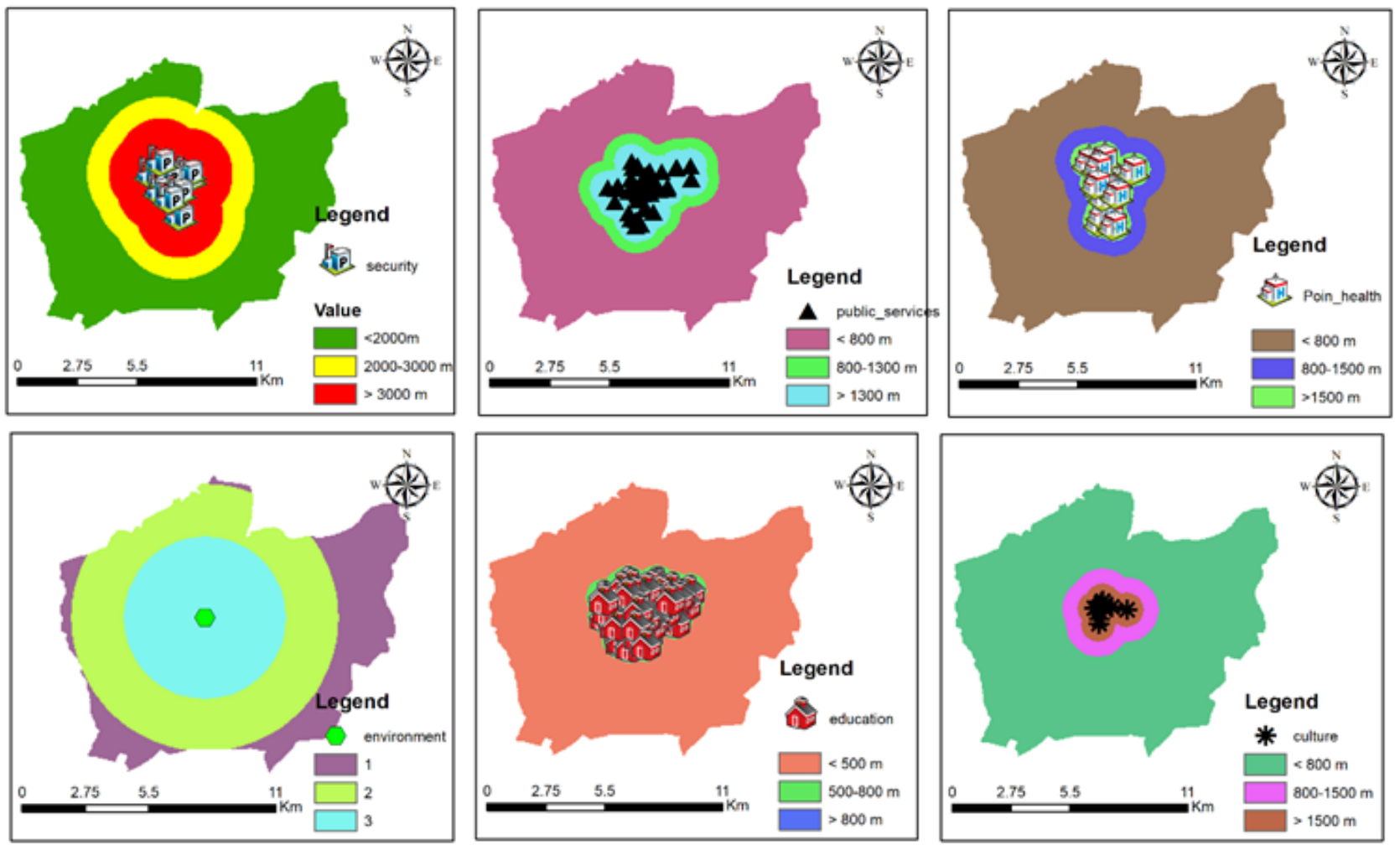

Figure 2. The criteria studied in analyzing the (QOL) in the city of Setif 

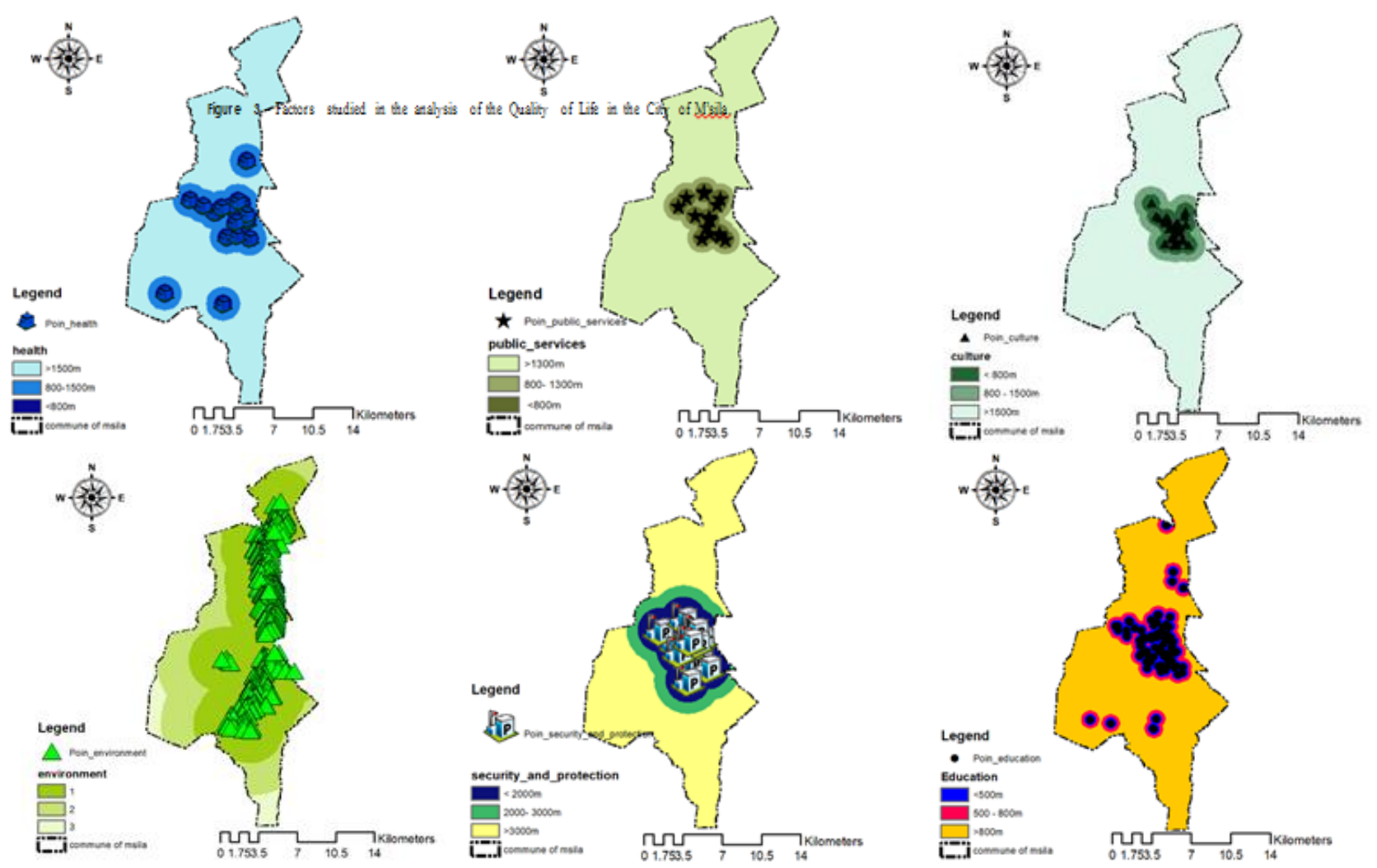

Figure 3. The criteria studied in analyzing the (QOL) in the city of M'sila
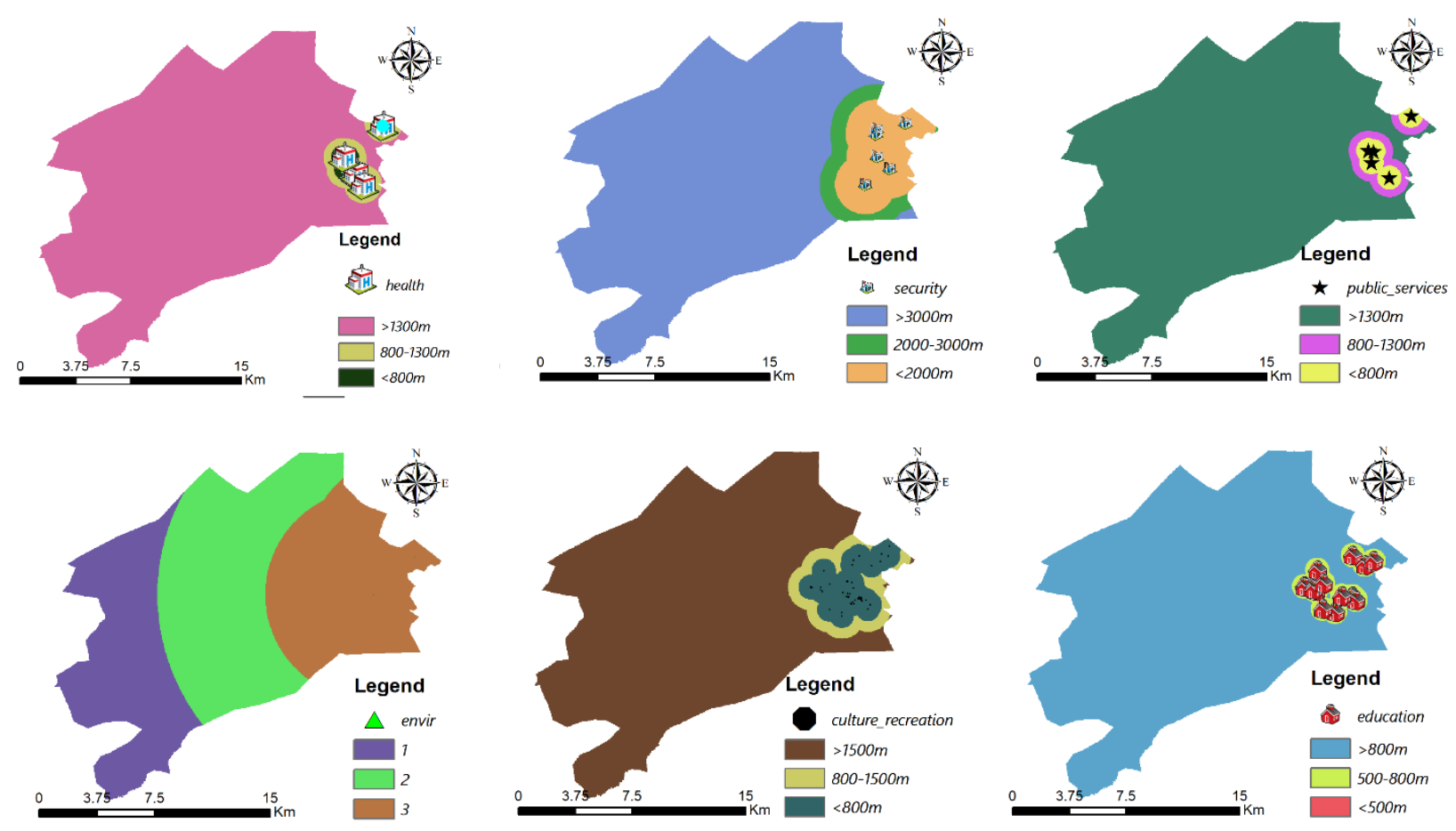

Figure 4. The criteria studied in analyzing the (QOL) in the city of Barika

\section{Methods}

Diagnosing an area, a prerequisite for any local planning, is "seen as an increase in the ability of actors in the region to control the processes that concern them (Boubir, 2018), as the study of a city system cannot be studied by looking at simple concepts only, such as land use or traffic, etc. The planners now need to develop and deepen their understanding of the city system by analyzing the various indicators (spatial, social, economic and environmental etc.). The issues that need to be addressed at the same time create a situation, as many alternatives must be tested and combined to improve the (QOL). Ludin et al., 2006, and choosing the best alternatives to create a balance and to work on an effective development in order to reduce the spatial disparities that the various cities suffer from. The research aims at extracting a map of spatial differences and assessing their differences in the three cities, and providing an appropriate framework, 
by merging the Delphi method, analytic hierarchy process (AHP), and (GIS). The same approach and criteria that were used in the previous study have been adopted: assessing the (QOL) in the city using the Delphi method and (AHP) and defining its spatial areas in the (GIS) environment: a case study on the city of M'sila / Algeria, in which we relied on experts from different disciplines, each of whom specialized in the field and has urban experience, with scientific and practical experience with knowledge of urban issues, (architects, urban planners, university professors, executive managers), and the second category is the citizens with no Professional knowledge but as actual users of this field; they know their needs and desires very well, and therefore their views can represent their actual needs to a large extent. by using the Delphi method, the researcher has come to extract six criteria stemming from the urban environment of their city, namely: (public services, education, environment, culture, entertainment and health, security and protection), as Delphi method is a systematic and interactive method that relies on a committee of experts, as an organized method of communication, to take interactive decisions based on the term "collective intelligence of experts", in order to give answers to questionnaires related to the topic In two phases Dalkey and Helmer, 1963; Sackman, 1974; Rowe and Wright, 2001, the researcher also relied on the (AHP) in extracting the weights of these criteria according to the opinions of the local population. To measure and extract a map of spatial differences, as this method enables us to help decision-makers to identify the cities that need balanced regional development, during preparing planning schemes and the territory in Algeria and limiting regional differences among the various regions of the country, especially the regions of the north, the high plateaux and the south, through a comparative study of three high plateaux cities (Setif, M'sila, and Barika). This type was developed by mathematician Thomas. "It is a quantitative method for assessing and arranging target-related alternatives." Thomas has identified an integrated framework that combines objective and subjective criteria, based on a relative-scale comparison. This method can provide a methodology for determining weights and assessing the different criteria used to assess the (QOL). By using (AHP), decision-making can be divided into several hierarchical levels so that a decision can be made based on the knowledge and experience of the relevant experts through a bilateral comparison at each Aalianvari et al., 2012; Saaty, 1980; Cheah et al., 2018; Yilmaz and Dagdeviren, 2016 (Figure 5). Then, the spatial data was collected by relying on the (QGIS) Program, the (QGIS) Platform is used by overlapping factors to create a map of the spatial differences for these cities based on data integration, geographic information systems analysis, and output evaluation where (GIS) is a system for creating, managing and analyzing graphics data Features and can be used as a decision-making support system by the manager, planner and decision maker. It is one of the most useful (GIS) applications for planning and management (Rad and Haghyghy, 2014). The purpose of integrating (GIS) is to inject spatial decision-making.

\section{Delphi method}

In this process, a group of experts from different disciplines who serve the research and have a leading authority that contribute to making various decisions have been relied upon. And their number was estimated at: 30 experts. The search followed four successive stages, starting with sending an anonymous summary containing a set of options and after each stage, we send an anonymous summary containing the outlook summary of the experts from the previous stage and the reasons on which their judgments were based, To the last stage, which is the fourth and final stage, after which the questionnaire results were determined (Qureshi et al., 2014). After this stage, six different and varied criteria were selected by experts, based on the opinion of the majority, and we stopped at these criteria: (Health, Public Services, Education, Environment, Culture and Recreation, Security and Protection). After completing the standard-setting process, we moved to another step, which is to involve the local population through the selection of a random sample in the evaluation of these standards through the use of a questionnaire to assess and reveal the spatial disparities of

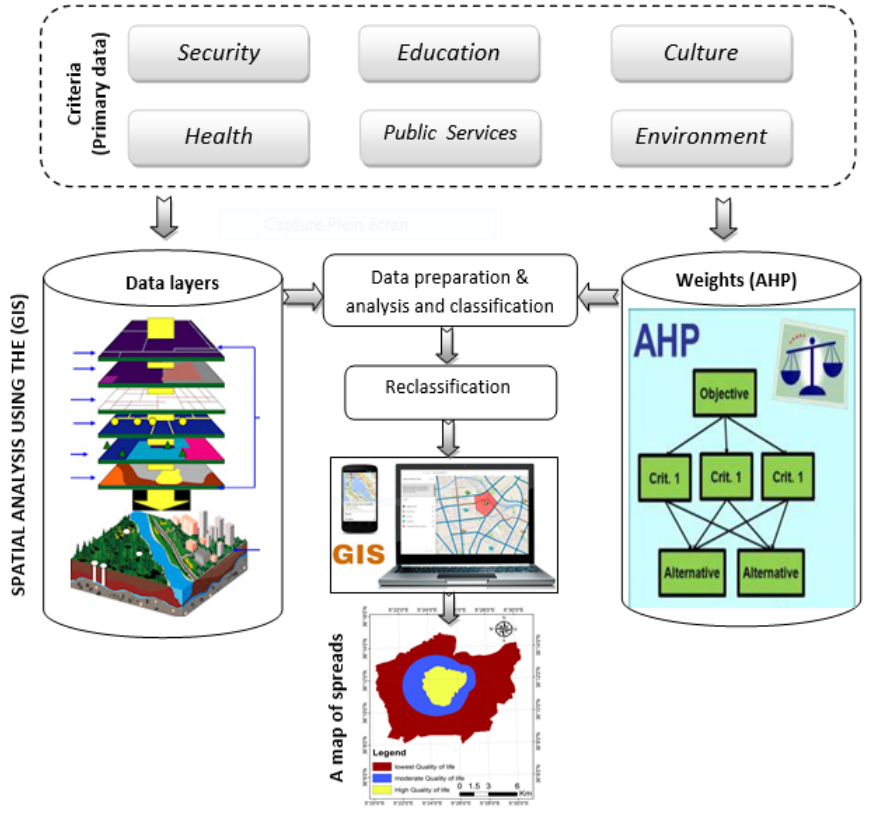

Figure 5. The methodology used in this research these cities. A range of survey questions were employed, including: What are your needs among these proposedcriteria? Is the distance between services and your various needs at home appropriate or not? Do these standards contribute to raising the quality of life for you and the city's residents as a whole? Then the degree of preference between the various main and sub criteria based on the opinion of the population was examined using the Thomas watchmaker's scale (Table 1), In order to compare the variables and take the opinion of the majority of the population on the (AHP) comparison, we proceeded to the process of analyzing the AHP hierarchy to determine the different weights of the main criteria and sub-criteria.

\section{Analytic Hierarchy Process (AHP)}

One of the most important aspects of this study is urban measurement and evaluation methods: it absorbs what is known about the city and evaluates its value, by comparing the three cities or extrapolating the performance in the future term. At 
present, there are a number of (MCDM) methods available for selection as a matter of the Analytical Hierarchy Process (AHP) The AHP approach, developed by (Satty, 1980), is one of the most widely used (MCDM) methods, is one (MCDA) is one of the most widely used methods. AHP has been applied to a variety of decisions and the human judgment process. (Lee et al., 2005). This technique is one of the methods (MCDM) with many capabilities. It is used in various scientific disciplines. Previous pieces of research indicate that (MCDA) technology; known as (AHP) is very suitable for solving complex problems (Yükse and Metin, 2007). It is widely applied in various fields. This method is very appropriate for social issues, and the complex spatiality in which intangible factors cannot be separated (Lee and Chan, 2008). Acquiring solutions in (AHP) is not a statistical measure, because it can help either one (or a group of decisions) decision maker to solve a problem (Chen, 2006) . (MCDM) is one of the most important advantages of (AHP) in terms of the ability to measure the quantitative and qualitative characteristics of a decision (Kangas, 1992). In addition to that, (AHP) is flexible in allowing the review; therefore, decision makers can expand hierarchy elements and change expert judgment from time to time.

2.1. Analysis: The (AHP) procedure is based on three basic steps:

(1) - Analysis includes or may refer to the establishment of a hierarchy.

(2) - Then come the judgments of comparison, or the identification and implementation of data collection to obtain binary comparison data about the elements of the hierarchical structure.

(3) - Then comes the process of collecting priorities, or building a comprehensive classification of priorities (Harker and Vargas, 1987). In the first stage, decision-makers need to divide decision-making problems with multiple complex criteria into their component parts, with all possible features arranged at multiple hierarchical levels. The criteria are not of equal importance to the decision at each level of the hierarchy and for each alternative rate differently from each criterion. (AHP) can provide an analytical process that is able to combine and standardize assessments of alternatives and standards by an individual or group involved in the decision-making task (Crouch and Ritchie, 2005). One notes that two elements are compared at a particular time that greatly reduce the conceptual complexity of the analysis. This simplification includes assumptions that (Saaty, 1980) considers reasonable, given the Binary comparison.

The analysis includes three tasks:

(1) - Develop a comparison matrix at each level of the hierarchy starting from the second level and working down.

(2) - Calculate the relative weights of each element of the hierarchy.

(3) - Estimating the consistency ratio to check the consistency of judgment (Boyer and Savageau, 1981). Comparisons can be made through personal or subjective judgments (Ho, 2008). The 9-point range used in the (AHP) studies ranges from 1 (indifference or equal importance) to 9 (extreme preference or absolute importance) (Table 1). This binary comparison enabled the decision maker to independently assess each worker's contribution to the purpose, thereby simplifying the decision-making process.

The program relies on the following factors: Analysis of a complex problem in a hierarchy of related decision elements. A thread hierarchy structure is created for all decision elements in the top-level hierarchy.

The global target is placed at the forefront of the pyramid's structure. The lower-level hierarchy consists of more detailed elements, which are linked to the criteria at the next higher level (Saaty, 1990).

2.2. Setting priorities: After the hierarchy is established, the relative importance of all precision components will be captured and detected by binary comparisons, which in turn are used to construct the ratio matrix. Binary comparisons are then made between the six major criteria and the sub criteria within the same hierarchical level, working to use the numerical scale as suggested by (Saaty), which ranges from 1 to 9, (Table 1) (Fagbohun and Aladejana, 2016); (Ouma and Tateishi, 2014).

It was obtained to extract the judgment matrices as follows: (Eq. 1).

$M=\left[\begin{array}{cccc}1 & \mathrm{a} 1 \mathrm{n} & \cdots & \mathrm{a} 1 \mathrm{n} \\ 1 / \mathrm{a} 12 & 1 & \cdots & \mathrm{a} 2 \mathrm{n} \\ \vdots & \vdots & \ddots & \vdots \\ 1 / \mathrm{a} 1 \mathrm{n} & 1 / \mathrm{a} 2 \mathrm{n} & \cdots & 1\end{array}\right]$

Eq (01) (Dehimi and Hadjab, 2019)

In this matrix, aij $=1 /$ aji. Thus, it can be noted that when $\mathrm{i}=\mathrm{j}$, it can be concluded that aij $=1$. Then, the decision matrix normalization process was performed, in which each value is divided by the sum of the values in each column, and in the end, we get the average of the row values (Kamali et al., 2017). Then the weights were obtained. This is to ensure consistency within the pairwise comparison matrix, then determine the consistency index (CI) according to (Eq2).
$\mathrm{CI}=\frac{\lambda \max -\mathrm{n}}{\mathrm{n}-1}$
Eq. (02)
(Dehimi and Hadjab, 2019) Where: $\lambda$ max expresses the largest value of the decision matrix. $\mathrm{n}$ : indicates the number of criteria used. According to this process, the final consistency ratio (CR) was obtained by (Eq.3) so as to measure the (CI) score (Table 2).

$\mathrm{CR}=\frac{\mathrm{CI}}{\mathrm{RI}} \quad$ Eq. (03) (Dehimi and Hadjab 2019) In this equation, (RI) stands for random consistency index. Its value is related to the dimensions of the matrix developed by Saaty, and if the value of (CR) exceeds (0.1), we must re-evaluate to improve consistency. The general purpose of the (AHP) is to support decision makers in choosing the best alternative from the various possible options for selection with multiple priorities.

\section{3. (GIS) and Analytic Hierarchy process (AHP)}

(GIS) technology has provided a distinct ability to automate and analyze a variety of spatial data, as it has evolved into a mature research and application area in various fields. Nowadays, (GIS) is a powerful tool in spatial modeling (Saaty, 
1982). It also allows for a comparative analysis of geographical information in space and time quickly (Yamashkin et al., 2020); which involves a large number of spatial resolution problems, which provide alternative scenarios in cartographic creation (Yaakup et al., 2005). Therefore, the integration of (MCDA) will provide a unique and useful solution to the problems associated with the problems of spatial decision (Saaty, 1982), (GIS) application has a significant impact on the dynamic nature of urban and regional development, where the application of (GIS) refers to high-level strategic planning to the regional scheme, the state structure scheme, and the level of planning. We are working to shed light on a wide scale, by identifying cities that need balanced regional development during the preparation of the (SNAT) and preparing the regional scheme for preparation and the region (SRAT) and reduce regional disparities among the different parts of the country.

\section{RESULTS AND DISCUSSION}

In our research, the application of (MCDM) in spatial problems and the application of (GIS) were discussed, and (AHP) was presented as a more appropriate tool in this context. This study presents a methodology and analytic tools for planning for spatial development. The research adopted the (MCDM) approach using (AHP) to extract the spatial differences map. In the (AHP), by implementing binary comparison matrices for each of the main factors and sub-factors included in the research. According to the purpose, six (06) criteria were used to evaluate the spatial area map for the three cities. Through professional ideas obtained from the checklists and according to the goal of gradually eliminating regional differences and disparities, encouraging development and integration between regions, and also working to improve the (QOL) in low-level areas and reduce the stark regional disparities between the various regions of the country, the weight of each criterion was determined. After extracting the relative weights for each criterion (Table 3), a map of the spatial differences was prepared. Then we compared and analyzed the results obtained. The result was the clear difference among the three cities in the (QOL) variation, even though being of the same social, cultural and natural environment.

Table 1. Shows the gradient scale for quantitative comparison of alternatives (Source: Abediniangerabi et al., 2014)

\begin{tabular}{|c|c|}
\hline VALUE & PREFERENCE LEVEL NUMERIC \\
\hline 1 & EQUAL PREFERENCE \\
\hline 3 & MODERATE PREFERENCE \\
\hline 5 & STRONG PREFERENCE \\
\hline 7 & VERY STRONG PREFERENCE \\
\hline 9 & ABSOLUTE PREFERENCE \\
\hline $2,4,6,8$ & INTER MEDIATE VALUES BETWEEN THEM \\
\hline
\end{tabular}

Table 2. Random indices from (Saaty, 1977)

\begin{tabular}{|c|c|c|c|c|c|c|c|c|}
\hline $\mathrm{n}$ & 3 & 4 & 5 & 6 & 7 & 8 & 9 & 10 \\
\hline $\mathrm{RI}$ & 0.58 & 0.9 & 1.12 & 1.24 & 1.32 & 1.41 & 1.45 & 1.49 \\
\hline
\end{tabular}

Table 3. Comparison of key criteria in (AHP) (Source: Dehimi, 2021)

\begin{tabular}{|c|c|c|c|c|c|c|c|c|}
\hline & Security & Education & Culture & Health & Public & Environm & Weight & Rank \\
\hline Security & 1 & 2 & 2 & $1 / 2$ & 1 & $1 / 2$ & 0.151 & 3 \\
\hline Education & $1 / 2$ & 1 & 1 & $1 / 2$ & 3 & $1 / 2$ & 0.135 & 4 \\
\hline Culture & $1 / 2$ & 1 & 1 & $1 / 5$ & 1 & $1 / 3$ & 0.084 & 6 \\
\hline Health & 2 & 2 & 5 & 1 & 2 & 1 & 0.273 & 1 \\
\hline Public & 1 & $1 / 3$ & 1 & $1 / 2$ & 1 & $1 / 3$ & 0.095 & 5 \\
\hline Environment & 2 & 2 & 3 & 2 & 3 & 1 & 0.261 & 2 \\
\hline & \multicolumn{2}{|c|}{$\lambda \max =6.29$} & \multicolumn{2}{|c|}{$\mathrm{CI}=0.05$} & $\mathrm{RCI}=1.2$ & \multicolumn{3}{|c|}{$\mathrm{CR}=5 \%$} \\
\hline
\end{tabular}

Table 5. Percentage of the (QOL) level for the three cities

\begin{tabular}{|c|c|c|c|c|c|c|c|}
\hline \multirow{2}{*}{ Numbere } & \multirow{2}{*}{ Categories } & \multicolumn{2}{|c|}{ Setif } & \multicolumn{2}{c|}{ M'sila } & \multicolumn{2}{c|}{ Barika } \\
\cline { 3 - 7 } & $\mathrm{Km}^{2}$ & $\%$ & $\mathrm{Km}^{2}$ & $\%$ & $\mathrm{Km}^{2}$ & $\%$ \\
\hline 1 & High quality of life & 14,50 & $11 \%$ & 7.99 & $03 \%$ & 3.98 & $01 \%$ \\
\hline 2 & Quality of life is moderate & 26,50 & $20 \%$ & 62.11 & $27 \%$ & 85.43 & $28 \%$ \\
\hline 3 & The lowest quality of life & 89,89 & $69 \%$ & 163.06 & $70 \%$ & 213.71 & $71 \%$ \\
\hline
\end{tabular}

The results of this research also demonstrated a spatial mismatch between the (QOL) and local economic development.

Finally, the Compliance Rate (CR) was calculated: (0.05), which indicates the validity of the model. These weights can be very useful for the national and regional planning that the authorities intend to do in the future (Table 3).

Then we extracted the procedures. The consistency ratio (CR $=0.05)$ was less than $(0.1)$ of the (Saaty) values in the first hierarchical level of the (AHP), apparently, the scale distribution between the factors was largely acceptable and showed good consistency (Shokati and Feizizadeh, 2019).
Table 4. Results obtained for: (AHP) between different main criteria and between different sub-criteria (Source: Dehimi and Hadjab 2019)

\begin{tabular}{|c|c|c|c|c|c|}
\hline Key criteria & Sub-Criteria & Weight & Rank & Final weight & Rank \\
\hline \multirow{3}{*}{ Security } & $<2,000 \mathrm{~m}$ & 0.574 & 4 & \multirow{3}{*}{0.151} & \multirow{3}{*}{3} \\
\hline & $2,000-3,000 \mathrm{~m}$ & 0.361 & 8 & & \\
\hline & $>3,000 \mathrm{~m}$ & 0.065 & 18 & & \\
\hline \multirow{3}{*}{ Education } & $<500 \mathrm{~m}$ & 0.717 & 1 & \multirow{3}{*}{0.135} & \multirow{3}{*}{4} \\
\hline & $500-800 \mathrm{~m}$ & 0.217 & 13 & & \\
\hline & $>800 \mathrm{~m}$ & 0.066 & 17 & & \\
\hline \multirow{3}{*}{ Culture } & $<800 \mathrm{~m}$ & 0.537 & 5 & \multirow{3}{*}{0.084} & \multirow{3}{*}{6} \\
\hline & $800-1,500 \mathrm{~m}$ & 0.364 & 7 & & \\
\hline & $>1,500 \mathrm{~m}$ & 0.099 & 14 & & \\
\hline \multirow{3}{*}{ Health } & $<800 \mathrm{~m}$ & 0.588 & 3 & \multirow{3}{*}{0.273} & \multirow{3}{*}{1} \\
\hline & $800-1,500 \mathrm{~m}$ & 0.323 & 10 & & \\
\hline & $>1,500 \mathrm{~m}$ & 0.089 & 15 & & \\
\hline \multirow{3}{*}{$\begin{array}{l}\text { Public } \\
\text { services }\end{array}$} & $<800 \mathrm{~m}$ & 0.649 & 2 & \multirow{3}{*}{0.095} & \multirow{3}{*}{5} \\
\hline & $800-1,300 \mathrm{~m}$ & 0.279 & 11 & & \\
\hline & $>1,300 \mathrm{~m}$ & 0.072 & 16 & & \\
\hline \multirow{3}{*}{ Environment } & Green areas & 0.413 & 6 & \multirow{3}{*}{0.261} & \multirow{3}{*}{2} \\
\hline & Public parks & 0.260 & 12 & & \\
\hline & Water bodies & 0.327 & 9 & & \\
\hline
\end{tabular}

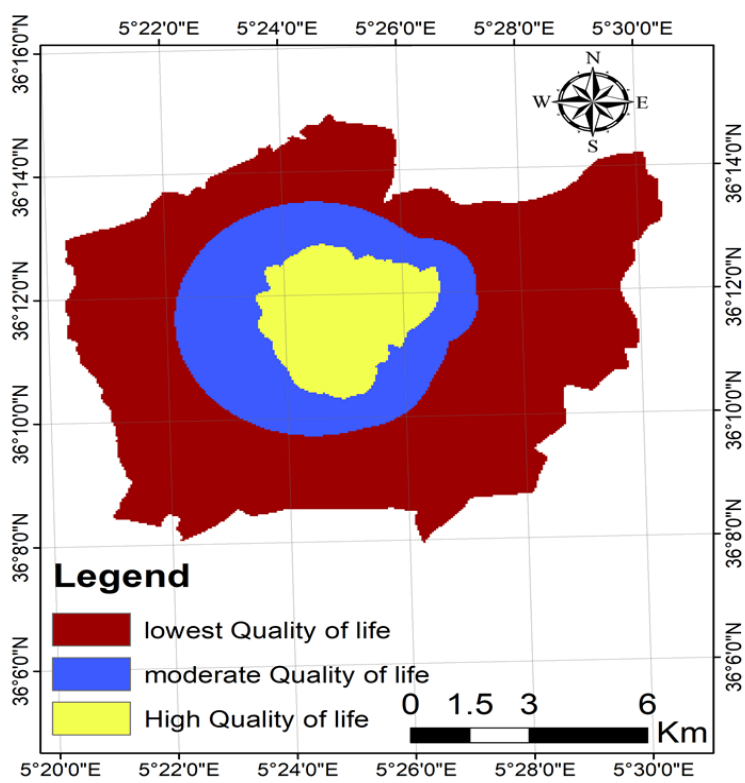

Figure 6. (QOL) Map of quality of life in City of Setif 


\section{RESULTS AND DISCUSSION}

In our research, the application of (MCDM) in spatial problems and the application of (GIS) were discussed, and (AHP) was presented as a more appropriate tool in this context. This study presents a methodology and analytic tools for planning for spatial development. The research adopted the (MCDM) approach using (AHP) to extract the spatial differences map. In the (AHP), by implementing binary comparison matrices for each of the main factors and sub-factors included in the research. According to the purpose, six (06) criteria were used to evaluate the spatial area map for the three cities. Through professional ideas obtained from the checklists and according to the goal of gradually eliminating regional differences and disparities, encouraging development and integration between regions, and also working to improve the (QOL) in low-level areas and reduce the stark regional disparities between the various regions of the country, the weight of each criterion was determined. After extracting the relative weights for each criterion (Table 3), a map of the spatial differences was prepared. Then we compared and analyzed the results obtained. The result was the clear difference among the three cities in the (QOL) variation, even though being of the same social, cultural and natural environment.

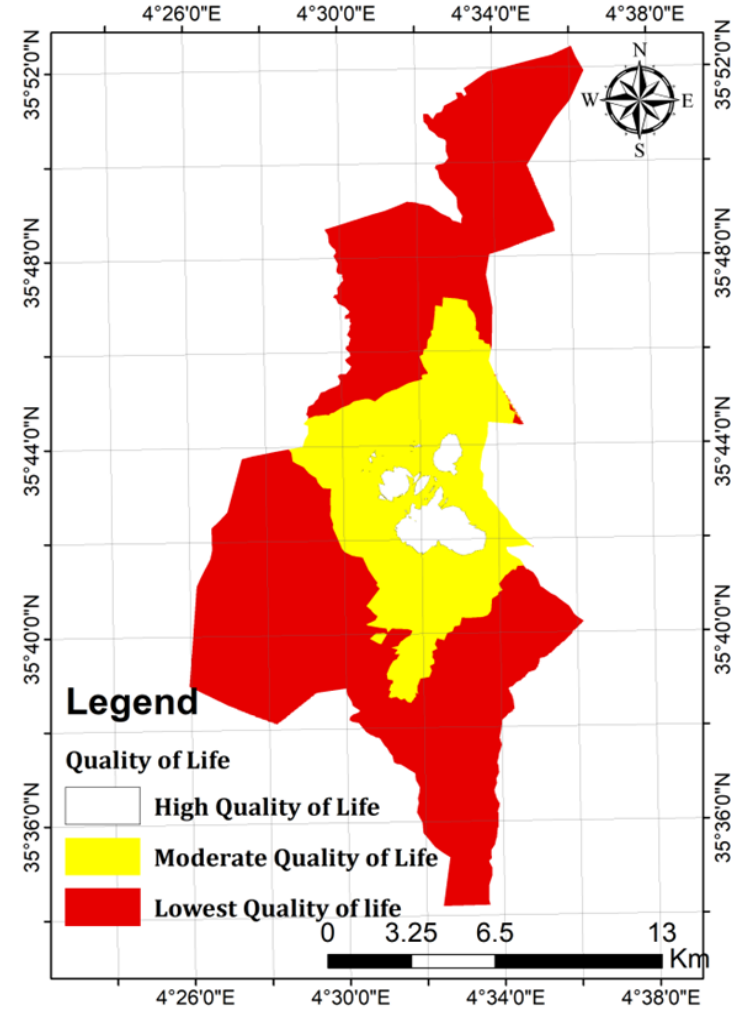

Figure 7. (QOL) Map of quality of life in City of M'sila

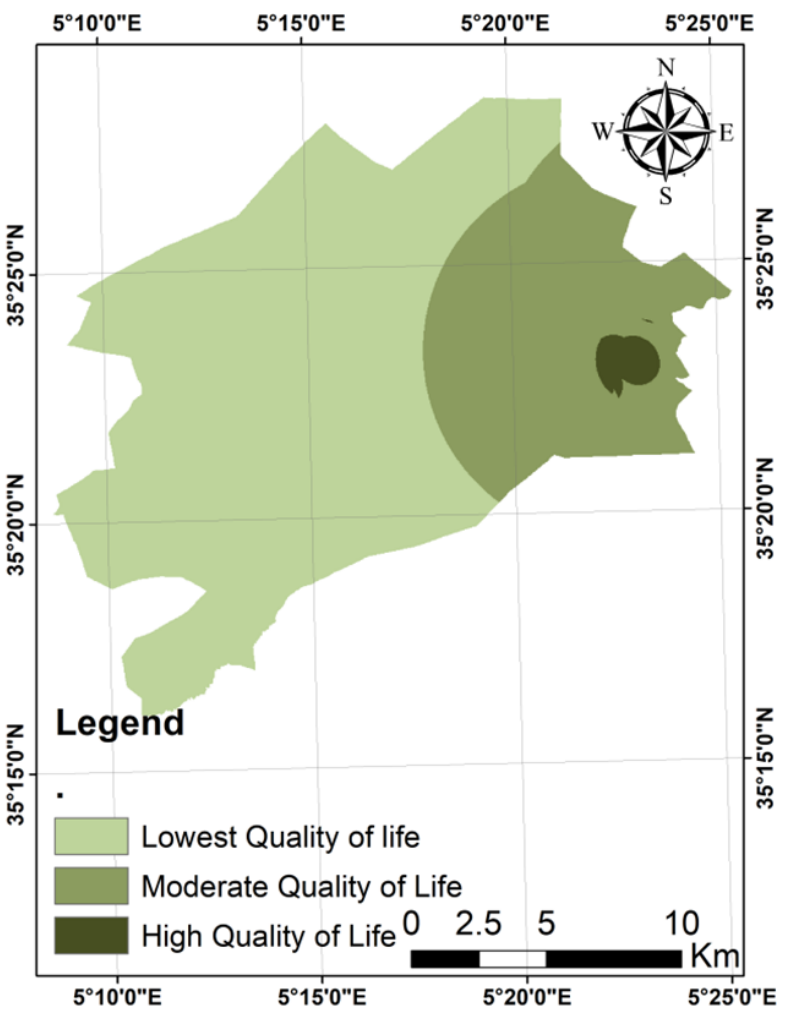

Figure 8. (QOL) Map of quality of life in City of Barika

According to the previous hierarchical analysis of (QOL) criteria selected in the city study, the role of (GIS) comes in the form of a draft summarizing all stages of work in "QGIS". Then we aggregate the pre-selected maps in the (GIS) software through point calculators with each criterion multiplied by the weight produced by the process (AHP), to extract the map of the three regions (Figure 6, 7 and 8).

By reading the quality of the map of the spatial differences of the three cities, it is noted that the regions that have achieved a high (QOL) according to: (AHP) are the province city center and its surrounding areas. i.e., there is a difference between the city's neighborhoods and the lack of equitable distribution of services and facilities. Setif came in the first degree with its achievement: $(11 \%)$ of the study area achieves a high (QOL) with an area estimated: $\left(14.50 \mathrm{~km}^{2}\right)$. While M'sila got: $(03 \%)$ of the study area achieves a high (QOL) with an area $\left(7.99 \mathrm{~km}^{2}\right)$, and the city of Barika came last with: $(01 \%)$ of the study area achieves a high (QOL) with an area $\left(3.98 \mathrm{~km}^{2}\right)$. We note the clear difference among the three cities in terms of the variation of the percentages of the (QOL), despite being of the same region and natural environment as mentioned above. While for the moderate (QOL), the city of Barika took the largest percentage by obtaining: (28\%) of the study area achieves a moderate (QOL) with an area estimated at: $\left(85.43 \mathrm{~km}^{2}\right)$.

While the city of M'sila obtained: (27\%) of the study area achieves a moderate (QOL) with an area $\left(62.11 \mathrm{~km}^{2}\right)$, and in the last came the city of Setif: $(20 \%)$ of the study area achieves a moderate quality of life with an area $\left(26.50 \mathrm{~km}^{2}\right)$, we note the great difference among the three cities, and how the proportions vary from one category to another, and as for the lowest (QOL), the city of Barika came as the first region to suffer from a low quality of life level by achieving: (71\%) of the study area that achieves a minimum (QOL) with an area estimated at: $\left(213.71 \mathrm{~km}^{2}\right)$. Then came the city of M'sila, with a ratio: (70\%) of the study area achieving a minimum quality of life with an area of $\left(163.06 \mathrm{~km}^{2}\right)$, and in the last came the city of Setif: $(69 \%)$ of the study area that achieves a minimum quality of life with an area estimated at: $\left(89.89 \mathrm{~km}^{2}\right)$.

\section{CONCLUSIONS}

Over the past years, Algeria has witnessed major structural and functional transformations that have created many 
changes in its field and society, this also have led to specific regional development at different spatial levels. The main scope of the study was to assess spatial differences, to identify and understand urban transformations and their spatial differences in relation to the social, economic and political changes of the country since independence.

In this research:

We came up to draw a map of the spatial differences of the high plateaux with three categories: high (QOL), moderate (QOL), and lowest (QOL). The results have shown that these three cities perform poorly in conditions of high (QOL), which are the main obstacles to ensure a better life. Health and environmental conditions are low, although the cities (Setif, M'sila, Barika) enjoy a relatively good material and natural environment, but it also shows clear deficiencies. As a matter of fact, these cities must be paid more attention in urban development in the future.

The above analysis reveals that the three cities differ greatly in terms of (QOL). The results of this research also demonstrate a spatial mismatch between the (QOL) and local economic development. The development of a multi-center network in the high plateaux region may contribute to the revitalization systems and raising the performance of these cities, which will contribute to the development of all regional systems. The development perspectives of settlements are linked to the ability of decision-makers to restructure the regional management system according to a new context, and to promote practical, sustainable and coherent development policies in the region, so that it can ensure systems of revitalization, and even transform some of the cities into centers or growth poles. The preoccupation of decision-makers in unifying the multi-center regional network will lead to the structuring of an effective system for transferring innovations and good practices from the national level to the local one, by strengthening the role of these cities, as well as establishing effective regional development.

Identifying gaps / differences in development identifies decision-makers to direct balanced development towards the high plateaux cities thanks to their great potentials, they can also reduce the pressure on the northern cities and re-optimize the population throughout the national territory. It is the main demand that the government, in its new policy, has adopted to establish foundations on the ground. The (SNAT) and (SRAT)focus on the role of the high plateaux cities in bringing the population and rebalancing the national domain that suffers from the high concentration of inhabitants in coastal areas, as Algeria relies on the high plateau cities to boost the Algerian economy for their important and abundant potentials.

The combination of Delphi method and the method of multi-criteria analysis through (AHP) in the environment (GIS) are effective methods that give more accurate results. This method has proven its effectiveness in helping decision makers to choose the best alternatives according to the factors determined by experts, in identifying different spatial discrepancies, and encouraging development and integration. However, these factors and indicators are subject to change by region. The results of the map can be used during the preparation of development plans in Algeria to reduce spatial disparities between the various regions of the country, work to improve the (QOL) in low-level areas, and help decision makers to establish balanced regional development in order to gradually eliminate regional differences and disparities and encourage development and integration between regions. Using the results of this study.

\section{REFERENCES}

Abediniangerabi, B., Fathi, S., Farahani, H.J., Kamalirad, S., \& Golshan, N.S. (2014). The MCDM application in urban planning projects: the CDS project of district 22 of Tehran municipality. Theoretical and Empirical Researches in Urban Management, 9(3), 55-69. https://www.researchgate.net/publication/286275533

Boubir, H.M. (2018). Une Stratégie Participative De Développement Local. Le Cas Du Territoire De Tébessa En Algérie [A Participatory Local Development Strategy. The Case of the Tebessa Territory in Algeria]. Romanian Journal of Geography, 62 (1), 99-113 (in French). http://www.rjgeo.ro/atasuri/revue\%20roumaine\%2062_1/Boubir\%20HM.pdf.

Boyer, R., \& Savageau, D. (1981). Places Rated Almanac. Rand monelly, Chicago.

Cheah, J.H., Memon, M.A., Chuah, F., \& Ting, H. (2018). Assessing reflective models in marketing research: A comparison between pls and plsc estimates. International Journal of Business and Society, 19(1), 139-160. https://www.scopus.com/inward/record.uri?Eid=2-s2

Chen, C. F. (2006). Applying the analytical hierarchy process (AHP) approach to convention site selection. Journal of Travel Research, 2. https://doi.org/10.1177/0047287506291593

Cote, M. (2010). Algérie. Le champ inversé Algeria [The Inverted Field]. K. A. Boudjemaa, Trans, Ain Mellila, Algeria.

Crouch, G.I., \& Ritchie, J.B. (2005). Application of the analytic hierarchy process to tourism choice and decision making: A review and illustration applied to destination competitiveness. Tourism Analysis, 10(1), 17-25. https://doi.org/10.1177/0047287506291593

Dalkey, N., \& Helmer, O. (1963). An experimental application of the Delphi method to the use of experts. Management science, 9(3), 458-467. https://doi.org/10.1287/mnsc.9.3.458

Dehimi, S. (2021). The use of new techniques in spatial modeling and analysis of urban quality of life: multiple-criteria decision analysis and gis. Geojournal of Tourism and Geosites, 35(2), 355-363. https://doi.org/10.30892/gtg.35213-659

Dehimi, S., \& Hadjab, M. (2019). Evaluating the quality of life in urban area by using the Delphi Method. A case study of M'Sila City/Algeria. Romanian Journal of Geography, 63(2), 193-202. http://www.rjgeo.ro/atasuri/revue_roumaine_63_2/dehimi,\%20hadjeb

Aalianvari, A., Katibeh, H., \& Sharifzadeh, M. (2012). Application of fuzzy Delphi AHP method for the estimation and classification of Ghomrud tunnel from groundwater flow hazard. Arabian journal of geosciences, 5(2), 275-284. https://doi.org/10.1007/s12517-010-0172-8

Fagbohun, B.J., \& Aladejana, O.O. (2016). Integrating knowledge-based multi-criteria evaluation techniques with GIS for landfill site selection: A case study using AHP. Materials and Geoenvironment, 63(3), 169-182. https://doi.org/10.1515/rmzmag-2016-0016

Fouad, B., \& Sawsan, K. (2020). Urban touristic development in the coastal cities case study Aqaba Alexandria Annaba and Casablanca cities. Geojournal of Tourism and Geosites, 29(2), 488-507. https://doi.org/10.30892/gtg.29209-484

Grigorescu, I., \& Kucsicsa, G. (2017). Spatial and temporal dynamics of urban sprawl in the Romanian Plain over the last century. Romanian Journal of Geography, 61(2), 109-123. https://www.researchgate.net/publication/322265232

Harker, P.T., \& Vargas, L.G. (1987). The theory of ratio scale estimation: Saaty's analytic hierarchy process. Management science, 33(11), 1383-1403. https://doi.org/10.1287/mnsc.33.11.1383 
Humeau, J.B., Peptenatu, D., Pintilii, R., Drăghici, C., \& Schvab, A. (2010). The Role of Polycentric Network in the Demographic Dynamic of Human Settlements. Journal of Urban \& Regional Analysis, 2(1). https://doi.org/10.37043/JURA.2010.2.1.8

Kamali, M., Alesheikh, A.A., Borazjani, S.A., Jahanshahi, A., Khodaparast, Z., \& Khalaj, M. (2017). Delphi-AHP and Weighted Index Overlay-GIS Approaches for Industrial Site Selection Case Study: Large Extractive Industrial Units in Iran. Journal of Settlements and Spatial Planning, 8(2), 99-105. https://doi.org/10.24193/JSSP.2017.2.03

Kangas, J. (1992). Multiple-use planning of forest resources by using the analytic hierrchy process. Scandinavian Journal of Forest Research, 4-1, 259-268. https://doi.org/10.1080/02827589209382718

Lee, G.K., \& Chan, E.H. (2008). The analytic hierarchy process (AHP) approach for assessment of urban renewal proposals. Social indicators research, 1, 155-168. https://doi.org/10.1007/s11205-007-9228-X

Lee, W.B., Lau, H., Liu, Z.Z., \& Tam, S. (2005). A fuzzy analytic hierarchy process approach in modular product design. Expert Systems. 32-42. https://doi.org/10.1111/1468-0394.00153

Ludin, A.N.M., Yaakup, A., Bakar, S.Z.A., Maidin, A., \& Ramle, L.H. (2006). GIS and planning support system for Klang Valley region, Malaysia. In Asia GIS 6th International Conference: 'GIS in Asia: Think Global Act Local', Universiti Teknologi Malaysia, Malaysia, 1-7.http://eprints.utm.my/id/eprint/572/2/GIS_And_Planning_Support\%282006\%29Ahmad_Nazri_Muhamad_Ludin.pdf

Maier, K. (2009). Polycentric development in the spatial development policy of the Czech Republic. Urban Research \& Practice, 2(3), 319-331. https://doi.org/10.1080/17535060903319285

Ouzir, M., Boudjemaa, K., \& Salim, D., \& Abla, K.A. (2021). Quantitative and qualitative assessment of urban green spaces in Boussaada City, Algeria using remote sensing techniques. Journal of Geography and Regional Planning, 14(3), 123-133. https://doi.org/10.5897/JGRP2021.0831

Marlina, Sumarmi, I Komang, A., \& Singgih, S. (2021). Social-economic adaptation strategies of bajo mola fishers in wakatobi national park. Geojournal of Tourism and Geosites, 34(1), 14-19. https://doi.org/10.30892/gtg.34102-613

Montgomery, M. (2007). United Nations Population Fund: State of world population 2007: Unleashing the potential of urban growth. Population and Development Review, 33(3), 639-641. http://www.un.org/en/aboutun/index.sh...

Ouma, Y.O., \& Tateishi, R. (2014). Urban flood vulnerability and risk mapping using integrated multi-parametric AHP and GIS: methodological overview and case study assessment. Water, 6(6), 1515-1545. https://doi.org/10.3390/W6061515

Pascariu, G. (2010). Evolution of the urban system of Botoşani County. Journal of Urban and Regional Analysis, 2(1), 39-60, http://www.jurareview.ro/

Qureshi, M.I., Bhatti, M.N., Rasli, A.M., Yasir, M., \& Zaman, K. (2014). The Delphi method for internationalization of higher education in Pakistan: integrating theory of constraints and quality function deployment. Mediterranean Journal of Social Sciences, 5(20), 2702. https://doi.org/10.36941/mjss

Rad, L.K., \& Haghyghy, M. (2014). Integrated analytical hierarchy process (AHP) and GIS for land use suitability analysis. World Applied Sciences Journal, 32(4), 587-594. http://idosi.org/wasj/wasj32 (4) 14/10.pdf

Rowe, G., \& Wright, G. (2001). Expert opinions in forecasting: the role of the Delphi technique. In Principles of forecasting, $125-144$. https://doi.org/10.1007/978-0-306-47630-3_7

Moghadam, F.S., Darvish, B., \& Javan, T.S. (2016). City and Urban Social Justice, Analyzing and Evaluating Regional Inequalities (Case Study: Eight Urban Deteriorated Districts of Zahedan City). J. Pol. \& L., 9, 112. https://doi.org/:10.5539/jpl.v9n6p112

Saaty, T.L. (1980). Analytic Heirarchy Process. Wiley statsref: Statistics Reference Online.

Saaty, T.L. (1977). A scaling method for priorities in hierarchical structures. Journal of mathematical psychology, 15(3), $234-281$. https://doi.org/10.1016/0022-2496 (77)90033-5.

Saaty, T.L. (1982). The analytic hierarchy process: A new approach to deal with fuzziness in architecture. Architectural Science Review, 25(3), 64-69. https://doi.org/ 10.1080/00038628.1982.9696499

Saaty, T.L. (1990). Decision making for leaders: the analytic hierarchy process for decisions in a complex world. RWS publications.

Sackman, H. (1974). Delphi assessment: Expert opinion, forecasting, and group process. Rand Corp Santa Monica CA.

Sarcheshmeh, M. H. H., Khakpoor, B. A., Shokuhi, M. A., \& Rahnama, M. R. (2020). Analysis of economic and social indicators in optimizing the performance of urban green space management (a study of Mashhad metropolis). GeoJournal of Tourism and Geosites, 32(4), 1370-1375. https://doi.org/10.30892/gtg.32426-582

Shokati, B., \& Feizizadeh, B. (2019). Sensitivity and uncertainty analysis of agro-ecological modeling for saffron plant cultivation using GIS spatial decision-making methods. Journal of Environmental Planning and Management, 62(3), 517-533. https://doi.org/10.1080/09640568.2018.1427561

Solaimani, K., Modallaldoust, S., \& Lotfi, S. (2009). Soil erosion prediction based on land use changes (a case in Neka watershed). American Journal of Agricultural and Biological Sciences, 4(2), 97-104. http://www.scipub.org/fulltext/AJAB/A...

Su, W., Gu, C., Yang, G., Chen, S., \& Zhen, F. (2010). Measuring the impact of urban sprawl on natural landscape pattern of the Western Taihu Lake watershed, China. Landscape and Urban Planning, 95(1-2), 61-67. https://doi.org/10.1016/j.landurbplan.2009.12.003

Yaakup, A., Ludin, A.N.M., Sulaiman, S., \& Bajuri, H. (2005). GIS in urban planning and management: Malaysian experience. In International Symposium \& Exhibition on Geoinformation, Geospatial Solutions for Managing the Borderless World, Pulau Pinang, 27-29. http://eprints.utm.my/id/eprint/506/2/gis_in_urban_plannin\%282005\%29ahris_

Yılmaz Kaya, B., \& Dağdeviren, M. (2016). Selecting occupational safety equipment by MCDM approach considering universal design principles. Human Factors and Ergonomics in Manufacturing \& Service Industries, 26(2), 224-242. https://doi.org/10.1002/hfm.20625

Yamashkin, A.A., Yamashkin, S.A., Aksyonova, M.Y., Cimbaljević, M., Demirović, D., Vuksanović, N., \& Milentijević, N. (2020). Cultural Landscapes Space-Temporal Systematization of Information in Geoportals for the Purposes of Region Tourist and Recreational Development. GeoJournal of Tourism \& Geosites, 29(2). https://doi.org/10.30892/gtg.29205-480

\footnotetext{
Article history: Received: 23.09.2021 Revised: 18.12.2021 Accepted: 26.01.2022 Available online: 21.02.2022
} 